\title{
Homeless Canadians' Perspectives on Homelessness in Calgary
}

\author{
Edith N. Ahajumobi, PhD \\ Walden University, Minneapolis, Minnesota, United States \\ Peter B. Anderson, $\mathrm{PhD}$ \\ Walden University, Minneapolis, Minnesota, United States
}

Contact: ahajumobi.nwadiohamma@waldenu.edu

\section{Abstract}

Since the 1990s, homelessness has increased in Canada, but the strategies of the government and public health service providers to manage the situation have had limited success. Researchers have also noted the lack of inclusion of those experiencing homelessness in homelessness research to better understand and develop a solution to the issue. In the present study, this is addressed through inclusion of homeless participants from diverse backgrounds. The purpose of this phenomenological study, framed by social cognitive theory, reciprocal determinism, and symbolic interaction, was to understand homelessness from the perspectives of people who do not have homes. Data were collected from open-ended interviews with a purposeful sample of 15 individuals who were homeless. Several themes emerged after interview data were transcribed via hand coding and analyzed using cognitive data analysis. The prominent themes were lack of money, home, privacy, and support; discrimination directed primarily toward First Nations people and those of African descent; mental illness and addiction; the need for a review of housing policy that addresses rent, mortgage qualification criteria, and house tax; and the creation of awareness of government support systems and the services that they provide. Public health service providers and designated authorities can use the findings of this study to understand the phenomenon from the perspective of people who are experiencing homelessness, which can influence the development of better homelessness reduction strategies that could improve the lives of those experiencing homelessness and their communities. Because homelessness is a public health issue, bringing it under control could positively impact the health and safety of the public.

Keywords: caregiver; homelessness; collaboration; cultural health capital; perspectives; policy development; Cause of mental health; discrimination and money problem; unemployment; neurorehabilitation

Date Submitted: March 1, 2019 | Date Published: May 23, 2020

\section{Recommended Citation}

Ahajumobi, E. N., \& Anderson, P. B. (2020). Homeless Canadians' perspectives on homelessness in Calgary. Journal of Social, Behavioral, and Health Sciences, 14, 106-122. https://https://doi.org/10.5590/JSBHS.2020.14.1.08 


\section{Introduction}

Homelessness across Canada has continuously increased since 1992 (Bell et al., 2015; Calgary Homeless Foundation, 2015; Komarnicki, 2014), and researchers have observed a steady rise in Calgary's homeless population (Komarnicki, 2014). The strategies to manage the situation have achieved limited success, perhaps due to insufficient research data (Awosoga et al., 2013), especially from qualitative studies focused on the experience of those affected. Existing homelessness strategies and policies have been developed based on individual risk factors, marginalization, exclusion, and economics (Aubry et al., 2019). For example, the Homelessness Partnering Strategy, a community-based program whose goal is to prevent and reduce homelessness in all provinces in Canada through direct funding, encourages longer term solutions and provides direct funding to communities to reduce and prevent homelessness, and the Housing First intervention programs are focused on moving people to permanent homes first before placing them in support services based on individual need (Aubry et al., 2019; Gaetz et al., 2014). Another example is a 10-year strategy (2008-2018) by the Calgary Committee to end homelessness which focused on having shelters for emergency temporary sheltering only, to ensure that no one slept outside and no one remained in an emergency shelter for more than seven days without moving to a safe, decent home (Gaetz et al., 2014; Homeless Hub, 2014).

Current research is not sufficient to support policy decisions and implementation (Awosoga et al., 2013; Calgary Homeless Foundation, 2016). The management of homelessness in Calgary can be improved by learning from those experiencing homelessness (Hubac \& Stroick, 2007). The Canadian Homelessness Research Network (n.d.) suggested that understanding the breadth and depth of the homeless phenomenon is the key to responding to it. The latest data available on homelessness in Calgary is from 2008-2014 (Calgary Homeless Foundation, 2015) leaving a gap in the research literature. In the current study, we explored homelessness from the perspectives of those experiencing homelessness using a phenomenological approach. This research fills a gap in the literature on homelessness in Canada and generates information that could be useful in finding solution to homelessness. Deeper comprehension could support homeless strategies and be integrated into development of policies or strategies that keep more people off the street and place more in permanent residences. Success with placing people in homeless situations into permanent homes contributes to the improvement of health and safety of those involved including the community (Aubry et al., 2019).

\section{What Is Homelessness?}

Homelessness is a situation where someone has lost their home and has no means to get another one (Public Health Service Act 42 U.S.C., 254b; Canadian Homelessness Research Network, n.d.). People may be temporarily at extended family members' or friends' homes; living in substandard buildings that lack heating and/or toilets; sleeping on couches, in cars, caravans, and/or in the corridors of a public building; and sleeping on the street (National Healthcare for Homeless Council, 2014). Homelessness involves having no money, job, family, friends, or community to provide support (Ahajumobi, 2017). The homeless population in Calgary consists of women fleeing from violence ( $65 \%$ of homeless women), people with jobs ( $40 \%$ of the homeless population, or 1,400 persons per night), children under 18 years old (about 300 per night), and people who are homeless because of income-related issues (Calgary Homeless Foundation, 2016). An especially vulnerable population is indigenous youth. Kidd et al. (2019) reported that indigenous youth were more likely than nonindigenous youth to suffer greater mental health and addiction challenges and that female and sexual and gender minority youth are particularly at risk for these challenges.

\section{Prevalence}

Homelessness has continuously increased in the city of Calgary. Over 3,000 people are homeless in Calgary every night, and there were 3,555 people without homes in October of 2014 (Calgary Homeless Foundation, 2014a). This population was comprised of children younger than 18, people between 18 and 64, women, 
people from the First Nations, and families (Calgary Homeless Foundation, 2014a). The population of homeless people in Calgary is continuously rising along with the housing demand. Ontarians (0.53\% of the adult population) experienced homelessness in 2016, a 67.3\% increase from 2007 (Richard et al., 2019).

There has been an increase of homeless people in shelters, which has decreased the number of those in jails and hospitals. The Calgary Homeless Foundation (2016) stated that between 2008 and 2012, the population of homeless rose from 1,512 to 1,715 in emergency shelters and increased from 1,224 to 1,260 in transitional housing (i.e., short-term, supportive housing). During this period, the numbers of those in the hospital and jail systems dropped from 296 to 151, a 49\% decrease, suggesting that accommodation in shelters and permanent homes decreases the tendency to get into trouble or be exposed to diseases (Calgary Homeless Foundation, 2016). The population of the homeless sleeping outside also dropped from 569 to 64 (88\%) during this same period (Calgary Homeless Foundation, 2016). Table 1 shows the history of the rise in homelessness in Calgary from 1992 (447) to 2014 (3,555).

Table 1. Homeless Statistics From 1992 to 2014

\begin{tabular}{lccccccccccc}
\hline & \multicolumn{10}{c}{ Demographic year } \\
\cline { 2 - 11 } & $\mathbf{1 9 9 2}$ & $\mathbf{1 9 9 4}$ & $\mathbf{1 9 9 6}$ & $\mathbf{1 9 9 8}$ & $\mathbf{2 0 0 0}$ & $\mathbf{2 0 0 2}$ & $\mathbf{2 0 0 4}$ & $\mathbf{2 0 0 6}$ & $\mathbf{2 0 0 8}$ & $\mathbf{2 0 1 2}$ & $\mathbf{2 0 1 4}$ \\
\hline $\begin{array}{l}\text { Homelessness } \\
\text { population }\end{array}$ & 447 & 461 & 615 & 988 & 1,296 & 1,737 & 2,597 & 3,436 & 3,601 & 3,190 & 3,555 \\
$\begin{array}{l}\text { Rough sleepers } \\
\text { Children }\end{array}$ & 5 & 41 & 30 & 38 & 168 & 117 & 127 & 429 & 569 & 64 & 182 \\
Women & & & & 70 & 129 & 115 & 218 & 304 & 384 & 81 & 434 \\
Youth & & 75 & 147 & 138 & 256 & 286 & 602 & 766 & 770 & 773 & 882 \\
Families & 20 & 37 & 28 & 85 & 196 & 219 & 296 & 100 & 195 & 271 \\
First Nations & & 25 & 28 & 36 & 30 & 42 & 104 & 104 & 197 & 160 & 211 \\
\hline
\end{tabular}

Note. Information from Komarnicki (2014) and Bell et al. (2015).

From Table 1, it is evident that there is a steady increase in the population of homelessness from 447 in 1992 to 3555 in 2014, except in 2012 when it dropped slightly and picked up again in 2014. Same with rough sleepers, it grew from five in 1992 to 182 in 2014. In 2012, the rough sleepers dropped sharply to 64 and tripled to 182 in 2014. Population of children followed similar pattern with the three above rose from 70 in 1988 to 434 in 2014, with a sharp drop to 81 in 2012, and multiplication of the 81 by 5.4 times in 2014. The population of homeless women maintained a steady rise from 75 in 1994 to 882 in 2014. Same with youth population, it grew from progressively from 20 in 1994 to 271 in 2014. Yet, families grew from 25 in 1994 to 211 in 2014, with a sudden drop to 160 in 2012. And First Nation population has known no drop but, progressively increased from 101 in 1994 to 515 in 2014. The populations of women, youth and first nations did not show any drop in 2012; even though other populations of people in homeless situation indicated slight to significant drops in 2012. Also, the population of children soured in 2014 to 434 from 81 in 2012, which was an excess of five times increase.

\section{Maintenance Cost and Health Problems}

There is a high prevalence of healthcare needs among the people experiencing homelessness that include mental health and addiction, which make the living conditions of people in a homeless situation difficult (Campbell et al., 2015). Researchers have suggested that more innovative solutions that include diverse groups of those in a homeless situation are required to address healthcare, advocacy, and other needs of those experiencing homelessness (Campbell et al., 2015). A condition like homelessness that affects the social, economic, mental, psychological, and physical health of the people is a public and community health concern 
(Aubry et al., 2019). Further, homelessness costs the Canadian government $\$ 53,144$ per person each year partially because of the high cost of maintaining homeless shelters (Aubry et al., 2019).

\section{Interventions}

The city of Calgary has made several interventions to end homelessness such as the homelessness partnering strategy and the Home First intervention program (Aubry et al., 2019; Gaetz et al., 2014). The latest homelessness intervention, sponsored by the government, was a 10-year strategy to ensure that no one slept outside in Calgary and no one remained in an emergency shelter more than 7 days without moving to a safe, decent home (Aubry et al., 2019; Gaetz et al., 2014). This intervention achieved some level of success at keeping people off the street but not in placing them in permanent homes (Gaetz et al., 2014). The Home First interventions were also only tested in small cities in Canada based on studies in the United States (Aubry et al., 2019).

In another intervention, authors reported that individuals having mental illness who were enrolled into the At Home/Chez Soi project experienced pathways to homelessness that consisted of individual variables namely, substance abuse, relationship conflicts, and mental illnes, as well as structural factors in foster care, and institutional barriers that unreasonably increased risk factors and prevented people from departing homelessness (Piat et al., 2015). In a follow-up to the original Piat study, Nelson and colleagues (2017) studied the success of At Home/Chez Soi and reported an overall $75 \%$ success rate in reduction of homelessness among approximately 2,000 participants.

Homelessness has been indicated among rural dwellers, when previously it was wrongly believed to be an urban problem. There yet exist challenges in determining its prevalence, and characteristics, and variables causing housing crisis among rural dwellers (Schiff et al., 2015). In 2015, only a 15\% drop in the homeless population was achieved in Calgary, and affordable housing remains a challenge (Bell et al., 2015). Placing people in homeless situations in supportive housing was indicated as a way to reduce health issues, hospital emergencies, and save the cost of maintaining homeless shelters (Bell et al., 2015). Lewis and colleagues (2016) agreed with the finding above and added that people experiencing homelessness are oppressed personally as well as by the culture and institutional structures that stand in the way for people to exit homelessness. Thus, despite these interventions, strategies and policies, a continuous rise in the homeless population and only $15 \%$ success in reducing homelessness, suggests a need for more studies on the topic (Aubry et al., 2019; Bell et al., 2015; Komarnicki, 2014).

\section{Gaps}

According to Schiff and colleagues (2015), addressing the homelessness problem is a priority for community health and safety and should be given a priority. Researchers have indicated a gap in homelessness research, strategies to combat the issue, and policy development (Gaetz et al., 2014). An in-depth understanding of the causes of homelessness could result in more strategies to lower the average cost of housing, provide service to the affected, and improve all homelessness-related policies (Aubry et al., 2019; Awosoga et al., 2013; Calgary Homeless Foundation, 2015). There is a need for continued data collection because evidence-based decisions are necessaryfor further research that could also assist people to exit homelessness (Calgary Homeless Foundation, 2015).

\section{Social Cognitive Theory}

The theory used in conducting this study was social cognitive theory. The proponents of this theory believe that the combination of a person's previous experiences (e.g., observations, reinforcement, expectations, selfefficacy, and expectancies) influence an individual's behavior (Bandura, 1997). Additionally, the theory suggests that a person is capable of action, and to achieve a healthy outcome, a person needs to know about a 
behavior and how to behave in the same way (Bandura, 2001). Further, behavioral knowledge and ability (behavioral capability) marks an individual's capacity to anticipate an outcome from situations (Mckenzie et al., 2009), which can be referred to as expectancy (Baranowski et al., 2002). Additionally, reinforcement is an integral component of social cognitive theory and can be self-motivated or rewarded (i.e., intrinsic; Baranowski et al., 2002). Reinforcement can also be indirect or motivated through direct reinforcement or verbal feedback (Baranowski et al., 2002).

Reciprocal determinism was also an important part of the theoretical foundation and refers to how a person's change in behavior impacts the environment in a reciprocal manner (Boston University, 2013). An individual's behaviors both influence and are influenced by the environment (Boston University, 2013). Additionally, reciprocal determinism involves the interplay between an individual's ability to acquire skills and a desire to alter a behavior (Bandura, 1997; Boston University, 2013). We also used the principle of symbolic interaction in this study. Symbolic interaction describes how facts or symbols are generated through human interactions based on the perceptions of the people involved (Mead, 2009; Symbolic Interaction Index, 2009). In accordance with the notion of symbolic interaction, behavior is based on what's believed about the social environment that contributes to the current lived experience of study participants.

The current qualitative study could play a significant role in learning about and understanding the phenomenon of homelessness. Greater understanding could lead to problem-solving the factors that lead to homelessness (see Polit \& Beck, 2014). More studies on homelessness can provide more evidence to support policy decisions and improve strategies to end homelessness (Aubry et al., 2019; Awosoga et al., 2013; Komarnicki, 2014). The current study provides anecdotal and demonstrative evidence from the diverse perspectives of those in homeless situations from diverse backgrounds-men, women without children, women with children, youth (youth indicated in this study are young adults aged 18-24), people of the First Nations, and the employed homeless (see Gaetz et al., 2014). The results of this study also add to the homeless literature in Calgary (see Awosoga et al., 2013; Calgary Homeless Foundation, 2015).

\section{Method}

Before collecting data, we obtained institutional review board approval (Number 01-20-17-0194616), then contacted a homeless agency's director of research for data collection through mail, telephone, and an inperson visitation. During the in-person visitation, we explained the study and its goal as well as answered questions. We also inquired about the procedure for meeting clients and an acceptable time duration and date for interviews. The agency agreed to partner with us, and we presented a flyer to post where it would be visible. We also requested permission to use a secure room for meetings with participants on interview days.

We collected data through in-depth interviews from those who stayed in a shelter aged 18-65 years old because in the shelter they have protection rather than being alone on the street (see Abdi, 2014; Boyce \& Neale, 2006; Mertens, 2015, p. 455). Participants were purposefully selected based on their ability to communicate and providing a diverse representation of those experiencing homelessness. Participants consisted of Canadians who were aged 18 to 65, currently experiencing homelessness who came from diverse ethnicities and racial backgrounds: Caucasians, First Nations, Africans, Asians, Europeans, Canadians, Americans, and South Americans. Among them were employed, unemployed, underemployed, pregnant women, family, veterans, and women and men who were separated or divorced. For our interviews, we used rooms that supported a private and comfortable environment. We used voice recording, notes, and member checking to verify the data before they were analyzed (see Creswell, 2011, p. 191). 
Table 2. Participant Demographics

\begin{tabular}{ccccc}
\hline Participant & Age & Gender & Race & Employment \\
\hline 1 & 48 & Male & White & Employed \\
2 & 34 & Male & Black & Employed \\
3 & 37 & Female & First Nation & Not employed \\
4 & 32 & Male & First Nation & Not employed \\
5 & 44 & Female & Asian & Not employed \\
6 & 29 & Male & Black & Not employed \\
7 & 64 & Male & White & Employed \\
8 & 41 & Female & Black & Employed \\
9 & 33 & Male & Black & Not employed \\
10 & 59 & Male & Asian & Not employed \\
11 & 21 & Female & White & Not employed \\
12 & 50 & Male & Asian & Not employed \\
13 & 53 & Female & First Nation & Not employed \\
14 & 38 & Female & White & Not employed \\
15 & 44 & Male & White & \\
\hline
\end{tabular}

We used a phenomenological design to conduct this study because it supported learning from participants' shared experiences of what homelessness meant to them (see Hoffman, 2014; Holstein \& Gubrium, 1995; Sokolowski, 2000). Further, hermeneutic phenomenology principles were used for retrieving, analyzing, and interpreting the perspective experience of respondents in a homeless situation (see Communication Theory, n.d.; Guba \& Lincoln \& Guba, 1994; Manen, 2007). These principles helped see participants' experiences from their viewpoint (Blumer, 1969). We used hand coding (i.e., identifying concepts and categories) and cognitive knowledge for data sorting, thematic grouping, categories assembling, and analysis of the data transcription. The use of data analysis software was not necessary. We only analyzed prominent participant statements among the themes (see Creswell, 2011, p. 184; Moustakas, 1994).

\section{Results}

This section includes interview data from the 15 participants as well as a discussion of the results. For data analysis, we used a hand-coding process. A cognitive process was used for data sorting to identify significant variables from the interviews, coding, theme assembling, category placement, theme clustering, data analysis, and synthesis. We organized the themes in three major groups, which represent the research questions: the lived experiences of those experiencing homelessness; life events or variables that keep people in homelessness, which were further subgrouped into government-, domestic-, and shelter-related variables; and a shelter that meets needs of the participants. The following prominent themes also address the three research questions: lack of money, home, privacy, and support; discrimination; mental illness and addiction; and the need for a review of housing policy that addresses rent and mortgage qualification criteria and house tax as well as better awareness of government support systems and the services that they provide.

Research Question 1: What are the lived experiences of those experiencing homelessness?

Three themes and 10 subthemes developed about the lived experiences of the people in homeless situation. 


\section{Theme 1: No Money, Home, Privacy, or Support}

In the lived experiences of people in homeless situations, the theme emerged of having nothing-no money, home, privacy, or support. In participants' own words, "Loss of job, loss of income, financial situation no money for bus, food, and everything that you need to live." "Left alone ... no family, no friend by your side." As a life event that keeps people in homelessness, the theme appeared as unemployment and a lack of employment skills and fixed income with no family support. Regarding a shelter that meets their needs, the theme of money surfaced as insufficient space and lack of resources and privacy (see Ahajumobi, 2017). This finding is congruent with previous studies (Calgary Homeless Foundation, 2015; Hubac \& Stroick, 2007).

\section{Theme 2: Discrimination}

Discrimination was also a central issue emerging in response to all three research questions (Gaetz et al., 2014) supported this theme, stating that discrimination is an obstacle to obtaining employment and other support services, which affects non-White racial and ethnic groups the most. In the current study, participants of African and First Nation descent expressed with tears in their eyes that their homelessness was due to racial discrimination or hatred. Participants added that discrimination is also a barrier to getting homes and receiving services, "Racial tension, ... Facing discrimination including racial." Researchers have also identified discrimination as a structural cause of homelessness that denies the opportunity to gain economic and social autonomy and stability that could prevent homelessness (Grenier et al., 2018; Gaetz et al., 2014; Piat et al., 2015).

\section{Theme 3: Mental Illness and Addiction}

All participants from diverse backgrounds mentioned mental illness and addiction, including gambling. Participants stated that some picked up the behaviour prior to becoming homeless while struggling with finances, unhealthy relationships, or an unsafe living environment. Some developed mental illness and addiction after they became homeless because of the stress and stigma. Some also reported becoming addicted because of bad friends: “. . . it has to be addiction, bad friends" "mental problems.” Additionally, some people with mental illness are homeless because they cannot manage their income well enough to live independently, and others have no income at all. All participants stated that mental disorders are common among the people at the shelter, especially schizophrenia, and having access to medication is a concern: " ... lots of schizophrenia, not having medications for psychiatric problem. Alcoholism, addiction of all kinds.” Previous researchers have also revealed that mental illnesses and addiction are high among the people experiencing homelessness (Campbell et al., 2015; Gaetz et al., 2014). Also, although mental illness, addiction, and relationship factors keep people in homelessness, institutional and structural factors entrench people more securely in homelessness (Piat et al., 2015). More structures that prevent people from securing good jobs are yet being put in place by policymakers. Parking, and traffic tickets cause insurance policy to increase, and in addition to phone bill all these fetch people bad credit history and in turn it prevents people from getting right jobs or qualifying for rent or mortgage.

Several subthemes emerged from the domestic variables that lead people into homelessness.

\section{Unsafe environment and home and/or bad roommate}

Respondents stated that they were living in an environment that is unhealthy, so they opted to live on the street. Some stated that they were abused by their spouses, and some hinted that their roommates had drug issues or were prostitutes, and sometimes their items or money went missing. Participants added, "I had a bad roommate that stole and cashed my check ... I left and came here”; "All my exes abused me.” Participants stated that to depart homelessness, people need a safe living environment. Even in shelters, participants expressed that it is a difficult situation due to lack of freedom because the shelters are regulated. Sleeping, 
eating, and showering follows shelter rules rather than when people want. However, to some participants, it is a place of freedom because when they were with abusive spouses, they had no freedom and safety.

\section{Separation and divorce}

Participants stated that they were homeless because of divorce or separation, which led to paying child support that they could not afford along with rent. Some stated that their spouses evicted them, and because they could not afford separate rents and cost of living, they became homeless. Participants' words are, "because of divorce, eviction, separations." Thus, the participants indicated a need to review policy on separation and divorce to address homelessness.

\section{Poor or lack of financial management skills and social skills}

Some respondents stated that their pension or income was enough to sustain a living; however, because they do not manage their funds well, they run out of money quickly. They could not retain their homes and pay for a living because they spent money on gambling, friends, or unnecessary things. Quotes from participants included, "they collect their benefits and spend it on drugs, alcohol, and gambling, and all kinds of addiction. they need help with rehabilitation, and with supervised spending." Participants stated that important for financial management training or support to help sustain a dignified living.

\section{Eviction}

Participants stated that they were evicted because they could not pay rent or because of a spouse or friend. Because they did not have other support, they became homeless: "eviction, you cannot pay rent, I lose my home." However, participants suggested that even if someone is evicted, if he or she had enough money or good paid job, they may not be homeless.

\section{Unemployment and lack of employment skills}

Respondents expressed that they became homeless because they were not employed, underemployed, or lost their jobs. Some were affected by the economic recession, but because they do not have other employment skills, they stayed unemployed for many years and remained homeless. Quoting from participants' own words: "Lack of more job skills"; "lose your job, new job skills training." Based on participants' responses, job skills training and regular full-time employment is needed for people to exit homelessness.

\section{Government-related variables}

Several subthemes appeared as government-related variables that lead people into homelessness.

\section{Racism and sexism}

Some participants expressed that discrimination was the cause of their homelessness. There was discrimination in employment, securing a house, and even at the shelter: "Police sometimes, pick up on a lot of people. they put you into trouble, our color, we get regular abuse for nothing ..."; "if you cannot pay your rent and bills, they send your name to credit bureau, you cannot get a job, rent or get mortgage." First Nations people and Africans were especially affected by this. From participants' experiences, discrimination needs to end to enable people to leave homelessness.

\section{Credit bureau and criminal record policy}

Respondents stated that they were homeless because when they lost their jobs and had no money to pay a simple phone plan, their names were submitted to credit bureau, which disqualifies them from getting good employment and getting a house. Here are participants' words: "if you cannot pay your rent and bills, they send your name to credit bureau, you cannot get a job, rent or get mortgage and even though you eventually get a job, you cannot rent or get a mortgage." Further, some stated that insurance will refuse to pay for repairs in a car accident for minority individuals. 


\section{Lack of affordable housing, rent, and mortgage qualification criteria, and house tax}

There were few affordable housing options in the city, and to some who may qualify, credit bureau and criminal records prevented them from getting it: "qualifications to get rent, or mortgage, to get references, high rent, ... high rent and mortgage conditions, criteria, and taxes. You can't get Alberta Works rent if you don't have any address." Additionally, participants indicated that the house tax is too high. Participants expressed that government can enable affordability of housing through making available low-cost housing, reviewing rent and housing conditions, and reducing house tax.

\section{Lack of government support system and discriminatory support system}

Some refuse to go to the shelter either because of ego or discriminatory treatment that they receive at the shelter. In participants' own words: "there should be a help for someone in need without having to be asked a thousand questions. For these questions, discriminatory treatment, $75 \%$ of the homeless give up on themselves." Participants stated that some get encouraging treatment and support and left homelessness quick, and some get the opposite.

\section{Economic recession, high cost of living, a fixed income, and new taxes}

Respondents recognized that the economic recession in Alberta from the drop in oil prices cost many their jobs, and personal and family income led them to homelessness. Additionally, they noted that there is a high cost of living in Calgary because some could not afford high cost of a home and utilities (electricity, water, sanitation, and gas). Some also have fixed income like pension or compensation entitlements, and none of the two can qualify someone to rent a house or get a mortgage. Participants expressed that charging new (additional tax) can render people homeless. Respondents suggested that it is crucial for government to stop increasing taxes and lower taxes and the cost of utilities.

\section{Colonialism}

Participants expressed that cultural factors prompted them into homelessness. First Nation participants indicated that separation from traditional lands, and communities, in addition to superstitious beliefs and manipulation by close family members restricted their freedom to work hard and do things to be independent of family members (Thistle, 2017). For example, one participant stated,

My mother made me her slave, she (wouldn't) allow me to go and work and do things on my own, my mother wanted me not to do anything by myself without her. She was manipulating me and my wife ... in the end we had problem and broke up. now that I am free, I will show her that I can do things or be somebody without her.

It affected their relationship with their spouses, causing the couple to break up. On the part of participants of African descent, cultural conflicts between them and spouse, and absence of family in Calgary led them into homelessness: "when I broke up with my spouse, I have no family here to run to for help, I became homeless."

Research Question 2: What are the life events that keep people in a homeless situation?

In answering the question concerning how people remain homeless, three themes and seven subthemes emerged, which were organized as government, domestic, or shelter.

\section{Theme 4: Child Support, Credit Bureau and Criminal Records, and Housing Tax}

Child support was a government- and domestic-related variable that keeps people in homelessness. Participants paid $65 \%$ of their income for child support, which left only $35 \%$ of their income to live on, making it difficult to depart homelessness. One participant stated, “... After child maintenance, I was left with only \$500. I can’t afford my own place.” Relationship factors such as family break-ups as a cause of homelessness has also been supported by previous research (Woolley, 2015), though child support is a new theme from this 
study. Participants specified that amending child support is necessary to help overcome homelessness. The participants also specified that credit bureau and criminal records affect employment and qualifying for rent or a mortgage (see Ahajumobi, 2017).

\section{Theme 5: Inefficient and Discriminatory Government Support Systems as Well as Lack of Support System Awareness}

The participants from various backgrounds stated that the absence of efficient support systems, including family, community, and the government, can be a cause of homelessness. "There should be a help for someone in need without having to be asked a thousand questions. For these questions, $75 \%$ of the homeless give up on themselves." A lack of awareness of the support systems was also an issue; thus, participants stated, "lack of awareness, not knowing who to turn to when in serious need." Awareness is necessary to inform the people experiencing homelessness and the community about the shelters, support systems, and the services they provide (see Ahajumobi, 2017). Better awareness was a new finding that was not reported by other researchers. All participants stated that before they became homeless, they did not know about shelters and other government support systems and the services that they provide, so they lived on the street and in their cars for as long as 1 year before going to a shelter.

No one tells you about being homeless, the shelters, and services they offer. Like I said in my own case, I am not entitled to work. If I can't work, what is the need of the job fair? I slept in my car for one year before police brought me to the shelter.

Respondents suggested that the government needs to create awareness of the shelters and support services so that people can avoid homelessness (see Ahajumobi, 2017). From the participants' experiences, it is necessary for people to explore the resources available for people in need of financial help because homelessness could happen to anyone. Further, it is essential that the government creates better awareness of the shelters and government support services.

\section{Shelter-related themes}

The following subthemes were developed about shelter-related reasons why people remain homeless.

Caring and people-oriented staff who are professionally trained like counselors, case workers, security staff, motivational speakers, and motivational support workers

From experience, participants believed that trained staff are essential to help people exit homelessness. Service providers require professional training, empathy, and a desire to assist people exit homelessness: "staff should be truly humanitarian and people driven"; "They should have motivational speakers and motivational support"; “. . . getting motivational speakers and people to motivate you"; " .. 75\% of the homeless give up on themselves.” Approaching people with a discriminatory or negative attitude affects whether they will cooperate or make an effort to depart homelessness.

\section{Insufficient space and resources}

Participants said that there was not enough space and resources at the shelter. Additionally, respondents expressed that some staff treated the resources like they were personally paid for, rather than from tax payers: "not enough tables and chairs. Every morning, there is a fight about tables and chairs. They need to build a bigger shelter, no enough spaces, more accommodation"; "more spaces, nutrition, beds, beddings, marts." Participants suggested increasing the shelter funding, accommodation, and other resources including food to enable people exit homelessness. 


\section{Agency policy on addiction and alcohol}

Agency policy forbids people from entering the shelter when they are drunk or intoxicated. However, participants commented that this places lives at risks, especially when people have no place to stay in extreme weather conditions: "before you are not allowed to come in here if you are not sober"; "... they leave people in the cold . . . -50. Many die in extreme cold"; "Now some allow them and place them in a pen, like a play pen." Respondents stated that shelters should accept those who are drunk but place them in different rooms with staff to attend to them. From the experience of participants, they need a warm space and resources, detoxification, and rehabilitation.

\section{Lack of categories of homelessness and lack of shelter for family}

Participants suggested that homeless shelters should be run in different categories because the needs of people in need of homes varies. Some do not need to spend as much time at a shelter and just need training or employment. Others need more rehabilitation or treatment. Additionally, some families or pregnant women have immediate needs: "they should put people with addiction and mental illness separate ... those on wheelchair separate"; "even seniors are here." Further, some families are not allowed to kiss or hug for fear of making others jealous, which compounds their feelings about their situation and makes it harder to depart homelessness.

\section{Wait time}

People who met the acceptance requirements of the shelter were accepted right away. There is no wait time, and people were taken in as soon as they arrived at the shelter after proper documentation and if they were sober: "when people are homeless and they come here, they should go straight and give them help they need." Participants applaud shelters for this; however, they said it was a challenge to leave, and some have stayed at the shelter for as long as 20 years.

\section{Security}

To some respondents, they were safe to be at the shelter because it offers protection. Others stated that the security at the shelter was poor. Some have brought in prohibited items, and some stated that they lost valuable items like cell phones and jackets because they lack private and secure place to keep their items and security cameras could not detect who stole the items. Quotes from participants include "I lost a jacket here, and cell phone. There are security issues here. The security checked and said that they didn't see anything. Now, I have a locker to secure my stuff. that makes me feel better." Losing some of these items caused grief and pain, which delayed exiting homelessness. Participants suggested that better shelter security such as secure lockers and space is necessary for a positive shelter experience to enable them exiting homelessness.

\section{Lack of training for job skills, financial management, and behavioral and social skills}

Participants also suggested that many have no home because of absence of necessary skills to gain employment. Quoting from participants' words, "if they have training tools to help people change their lives, like courses, and classes, money management courses." Participants believe that more skills and training would assist them to depart homelessness.

Research Question 3: How would people in a homeless situation describe a shelter that would meet their shelter needs?

The results for Research Question 3 show how a shelter could meet the needs of the homeless through five themes. 


\section{Theme 6: Caring and People-Oriented Trained Staff}

The participants reported that a trained and caring staff is central to the people at the shelter overcoming homelessness: "It depends on who is working that day. There are some good people and some bad people." If the people at the shelter know that the staff care and want to assist them in getting out of homelessness, then people at the shelter will cooperate, feel motivated, and do their best to exit homelessness. Participants stated that "They should have motivational speakers and motivational support"; " . . getting motivational speakers and people to motivate you." However, negative staff attitudes can make bad habits worse. This factor was stated by all participants but two. This was a new finding not suggested by earlier researchers.

The respondents from diverse backgrounds expressed a desire for training shelter staff to a professional level Gaetz and colleagues (2014) indicated that professional training and improved strategic planning is achievable for shelter staff but only when based on appropriate evidence. Respondents also encouraged having motivational speakers and motivational support staff (see Ahajumobi, 2017). This theme occurred in response to all research questions but one, and it was a new finding not suggested by previous researchers.

\section{Theme 7: Training on Job Skills, Anger Management/Relationship Skills, and Spending Skills}

Lack of skills was expressed by the respondents as a cause for people at the shelter remaining homeless. Many get enough money, but they can't control spending: "They collect their benefits and spend it on drugs, alcohol, and gambling, and all kinds of addiction. They need help with supervised spending of their income to avoid wasting the money and placing themselves at higher risks." Providing training on these skills to the people at the shelter and or helping them to manger spending, "if they have training tools to help people change their lives, like courses, classes, money management courses." "Lack of more job skills" "by getting more training to help me obtain more employment" would aid them in overcoming homelessness (see Ahajumobi, 2017). Participants would prefer full-time employment to exit homelessness. Respondents also stated that an information office would be beneficial because it helps them to know where to go to seek help to leave homelessness.

\section{Theme 8: Sports, Recreational, and Wellness Programs}

The respondents from diverse ethnicities and racial backgrounds expressed that having sports, recreation, and wellness programs at the shelter is important to help people depart homelessness: "recreation facilities, going for an hour walk, play volleyball etc."; "the wellness classes, and gardening group because, it is peaceful." Participants stated that they would prefer to play sports or games than do drugs: "I really, prefer to get up and go and play soccer than to go and drink" (see Ahajumobi, 2017). This finding was new; it was not reported by previous authors. This finding was new, it was not suggested by other authors.

\section{Theme 9: Improve Security, Safety, Privacy, Hygiene, and Maintenance of Shelters}

From the diverse participants' experience, homeless shelters need to be safe, secure, offer reasonable privacy, and maintain hygiene: "Bed bugs, maintenance, they need to update things inside the building, maintenance should take place every 6 months to 2 years.” If people have poor health conditions, they cannot exit homelessness. This finding is concurrent with previous research that suggests the prevalence of health issues among individuals who are homeless (Campbell et al., 2015).

\section{Theme 1o: Long Wait Periods and Unnecessary Questions and Protocols}

Experience informed the diverse participants from various backgrounds that long waiting, and unnecessary questions and protocols will keep people more in homelessness. Some will rather not seek help than answer the questions: “. . they should go straight and give people help they need”; "not pushing people here and 
there." This is a new finding that was not reported by previous authors. Participants also stated that some shelters run $24 \mathrm{hr}$. To respondents, this was beneficial because sometimes people could be kicked out in the middle of the night. Quoting from participants' own words, "it is about the shelter that opens-up all day 24seven.” Additionally, people who were resisting to seek help from shelter could decide anytime to go and ask for help from a shelter.

\section{Discussion}

Based on the 10 prominent themes, the environment affects people in homeless situations and their experiences affect the environment, which aligns with social cognitive theory and reciprocal determinism. Additionally, from the lived experiences of the diverse participants, social structures are best described and understood in terms of individual interactions at multiple levels of social relationships, thus, symbolic interaction constructs were apparent. Thus, homelessness can be understood from their perspectives, which supports the phenomenological approach of this study.

\section{Recommendations for Further Studies}

We recommend that researchers replicate this study with a larger sample of homeless participants and a goal of going beyond describing and understanding the experiences of the homeless respondents to interpretation of their responses to build a more complete picture of the homeless population in Canada. We also recommend that researchers conduct studies on lung diseases and mental illness prevalence, including schizophrenia, dementia, depression, and addiction, among people in a homeless situation and how to control these illnesses. People who are homeless are often preyed upon and studies to assess the prevalence and outcomes of violence and sexual exploitation of those experiencing homelessness could lead to improved understanding of perpetrators, victims, and the expansion of services to remedy this exploitation. Conducting more studies to determine how to categorize the homeless in service-delivery to meet their various needs is also important to ending homelessness.

\section{Implications}

The results of this study to have significant implications for the homeless, public, researchers, service providers, and policymakers. The findings also add to the body of homeless literature in Calgary and Canada, especially regarding the diverse perspectives of those experiencing homelessness. The findings may help in keeping people off the street and placing them in permanent residences. Successfully placing people in permanent homes contributes to the health and safety of those involved (Aubry et al., 2019) as well as the city of Calgary.

\section{Limitations and Trustworthiness}

We did not measure relationships or count population in this study. We only conducted a descriptive and explanatory analysis of the interview data from the lived experiences of people in a homeless situation. Additionally, some respondents who shared experiences could have missed the point or focus of the conversation, which was addressed through triangulation (see Moustakas, 1994; Newton \& Rudestam, 2007, p. 40).

We selected the respondents purposefully (see Newton \& Rudestam, 2007, p. 107), ensuring that samples were selected from Canadian people from diverse ethno-racial backgrounds living at a shelter who saw our poster announcement, came for our information session, and consented to participate. The room was secure and conducive for safety and privacy. Participants were also informed to share only the experiences that they 
want to share and stop sharing whenever they wanted and indicate that by a wave of hand. They received a gift card token from us after each meeting.

Because this study was qualitative and subjective, biases were likely. We obtained the data based on the individuals' present and past homeless experiences (i.e., retrospective), which they may have forgotten, overstated, or understated. We collected data and reflexively interpreted it, which could also be a potential source of bias (see Abdi, 2014; Mertens, 2015, p. 454; Moustakas, 1994; Newton \& Rudestam, 2007, p. 40). To mitigate this possible bias, we cross-checked the interview data by taking notes and voice recording for member checking before proceeding with data analysis. We were transparent and objective in analyzing, interpreting, and reporting the data, and we tried to avoid personal influence and bias. Further, phenomenological studies are naturally prone to bias (Newton \& Rudestam, 2007, p. 39); however, the credibility of this study lies in its consistency in measuring what it was set to measure and its replicability (see Newton \& Rudestam, 2007, p. 113). We confirmed the validity of this study through detailed data description and by including discrepant outcomes (see Creswell, 2011).

\section{Conclusion}

From the diverse perspective of participants experiencing homelessness; homelessness means that a person has no money or support network and is exposed to danger and abuse. The participants' experiences suggest that there is no one single variable that leads or keep people into homelessness. Discrimination, money issues, housing policies, and environmental/structural and domestic variables lead and keep people into homelessness. Considering the government related variables that lead people into homelessness, participants also suggested that policymakers need to review the government policies on employment, housing, divorce and separation, child support, criminal records, credit bureaus, and the provision of skills training to assist people exiting homelessness. Additionally, professionally trained, people-oriented staff including motivational speakers and motivational support staff are critical to ending homelessness. And a safe, secure and good hygienic shelter with adequate privacy and recreational activities among others meets the needs of people at the shelter. Individual characteristics and behaviors as well as environment led the participants to homelessness, but their experience taught them lessons that empower them to change behaviors that are not healthy and support them to exit homelessness. Thus, this study provides information about homelessness that can benefit the homeless, public, researchers, public health service providers, and policymakers by influencing homeless and public health strategies and policy decisions. The results of this study also add to the body of homeless literature in Calgary and Canada.

\section{References}

Abdi, A. (2014). The effect of inquiry-based learning method on students' academic achievement in science course. Universal Journal of Educational Research, 2, 37-41. https://doi.org/10.13189/ujjer.2014.020104

Ahajumobi, E. N. (2017). Homelessness in Calgary from the perspectives of those experiencing homelessness. http://scholarworks.waldenu.edu/dissertations/441

Aubry, T., Bourque, J., Goering, P., Crouse, S., Veldhuizen, S., LeBlanc, S., Cherner, R., Bourque, P., Pakzad, S., \& Bradshaw, C. (2019). A randomized controlled trial of the effectiveness of Housing First in a small Canadian City. BMC Public Health, 19, 1154https://doi.org/10.1186/s12889-019-7492-8

Awosoga, O., Belanger, Y. D., \& Head, W.G. (2013). Homelessness, urban aboriginal people, and the need for a national enumeration. Open Journal System, 2(2), 4-33. https://doi.org/10.5663/aps.v2i2.19006

Bandura, A. (1997). Social learning theory. Prentice Hall. 
Bandura, A. (2001). Social cognitive theory and clinical psychology. International Encyclopedia of the Social \& Behavioural Sciences, 14250-14254. https://doi.org/10.1016/Bo-08-043076-7/01340-1

Baranowski, T., Perry, C. L., \& Parcel, G. S. (2002). How individuals, environments, and health behaviour interact. In Glanz, K., Rimer, B. K., Lewis, F. M. (Eds.), Health behaviour and health education: Theory, research, and practice (3rd ed., pp. 165-184). Jossey-Bass.

Bell, M., Jackson, N., Jadidzadeh, A., \& Kneebone, R. (2015). Who are the homeless? Numbers, trends and characteristics of those without homes in Calgary. The School of Public Policy SPP Research Papers, $8(11), 1-16$.

Blumer, H. (1969). Symbolic interactionism: Perspective and method. Prentice-Hall.

Boston University. (2013). Behaviour change models: Social cognitive theory. http://sphweb.bumc.bu.edu/otly/MPH-Modules/SB/SB721-Modules/SB721/Modules5.html

Boyce, C., \& Neale, P. (2006). Conducting in-depth interviews: A guide for designing and conducting indepth interviews for evaluation input. http://www.pathfind.org/site/pageserver?pagename=publications FOCUS Guides and Tools

Calgary Homeless Foundation. (2014a). Point-in-time count report. http://calgaryhomeless.com/wpcontent/uploads/2014-Fall-PIT-Report_Calgary.pdf

Calgary Homeless Foundation. (2014b). The 10-year plan to end homelessness. http://calgaryhomeless.com/wp-content/uploads/2014/o6/The-Cost-Benefits-of-Housing-First.pdf

Calgary Homeless Foundation. (2015). Together, we will end homelessness in our communities by being a catalyst and enabler for service agencies and the systems to optimize client success. http://calgaryhomeless.com/content/uploads/15.06.15 CHF AnnualReport LowrezPages.pdf

Calgary Homeless Foundation. (2016). Ending homelessness: The societal impact. http://calgaryhomeless.com/content/uploads/CHF-Annual-Report-FINAL.pdf

Campbell, D. J. T., Gibson, K., O’Neill, B. G., \& Thurston, W. E. (2015). Primary healthcare needs and barriers to care among homeless populations. Journal of Biomedical Central Family Practice, 16, 139. https://doi.org/10.1186/s12875-015-0361-3

Canadian Homelessness Research Network. (n.d.). Definition of homelessness. http://www.homelesshub.ca/ResourceFiles/CHRNhomelessdefinition-1pager.pdf

Communication theory. (n.d.). Hermeneutics. http://communicationtheory.org/hermeneutics/

Creswell, J. W. (2011). Research design: Qualitative, and mixed methods approaches (3rd ed.). Sage.

Gaetz, S., Gulliver, T., \& Richter T. (2014). The state of homelessness in Canada 2014 (Homelessness Hub Paper Number 5). http://www.homelesshub.ca/sites/default/files/SOHC2014.pdf

Grenier, S., Menard-Dunn, M., \& Laliberte, A. (2018). Indigenous itinerancy: Between nomadism and dispossession. Canadian Psychology/Psychologie Canadienne, 59(1), 100-106.

Griffith, J. R. (2017). Perception of shelter workers on the barriers the homeless face in obtaining and maintaining long-term housing (Doctoral dissertation). https://scholarworks.waldenu.edu/dissertations/3682/

Healthcare for Homeless Council. (2014). What is the official definition of homelessness? http://www.nhchc.org/faq/official-definition-homelessness/

Hoffman, W. (2014). What is phenomenology? http://www.maxvanmanen.com/files/2014/03/What-isphenomenology.pdf 
Holstein, J. A., \& Gubrium, J. F. (1995). Qualitative research methods: The active interview. Sage. https://doi.org/10.4135/9781412986120

Homeless Hub. (2014). Calgary, AB: Population facts. http://www.homelesshub.ca/communityprofiles/alberta/calgary

Hubac, L., \& Stroick, S. M. (2007). Homelessness: What do we know? http://www.homelesshub.ca/ResourceFiles/dzwltrid.pdf

Kidd, S. A., Thistle, J., Beaulieu, T., O'Grady, B., \& Gaetz, S. (2019). A national study of Indigenous youth homelessness in Canada. Public Health, 176, 163-171. https://doi.org/10.1016/j.puhe.2018.06.012

Komarnicki, J. (2014, February 21). Calgary homeless numbers holding steady, count finds. Calgary Herald. http://www.calgaryherald.com/news/Calgary+homeless+numbers+holding+steady+count+finds/95 32621/story.html

Lewis, T. R., Lorenzetti, Murwisi, P., St-Denis, N., \& Walsh, C. A. (2016). Community voices: Insights on social and human services from people with lived experiences of homelessness. Review of Social Sciences, 1(2), 27-41.

Lincoln, Y. S., \& Guba, E. G. (1994). We are pleased to accept your invitation. Evaluation Practice, 15(2), 179192. doi: 10.1016/o886-1633(94)90008-6

Manen, M. V. (2007). Phenomenology of practice. Phenomenology \& Practice, 1(1), 19803. https://doi.org/10.29173/pandpr19803

Mckenzie, J. F, Neiger, B. L., \& Thackeray, R. (2009). Planning implementing \& evaluating health promotion programs (5th ed.). Pearson Benjamin Cummings.

Mead, G.H. (2009). Mind, self, and society from the standpoint of a social behaviourist. Chicago Press.

Mertens, D. M. (2015). Research and evaluation in education and psychology: Integrating diversity (4th ed.). Sage.

Moustakas, C. (1994). Phenomenological research methods. Sage.

National Healthcare for Homeless Council. (2014). What is the official definition of homelessness? http://www.nhchc.org/faq/official-definition-homelessness/

Nelson, G., Caplan, R., MacLeod, T., Macnaughton, E., Cherner, R., Aubry, T., ... Goering, P. (2017). What happens after demonstration phase? The sustainability of Canada's At Home/Che Soi, housing first programs for homeless persons with mental illness. American Journal of Community Psychology, 59, 144-157.

Newton, R. R., \& Rudestam, K. E. (2007). Surviving your dissertation: Comprehensive guide to content and process (3rd ed.). Sage.

Piat, M., Polvere, L., Kirst, M., Voronka, J., Zabkiewicz, D., Plante, M.-C., Isaak, C., Nolin, D., Nelson, G., \& Goering, P. (2015). Pathways into homelessness: Understanding how both individual and structural factors contribute to and sustain homelessness in Canada. Urban Studies, 52(13), 2366-2382. https://doi.org/10.1177/0042098014548138

Polit, D. F., \& Beck, C. T. (2014). Essentials of nursing research: Appraisal evidence for nursing practice (8th, ed.). Wolters Kluwer.

Richard, L., Hwang, S., Forchuk, C., Nisenbaum, R., Clemens, K., Wiens, K., Booth, R., Azimaee, M., \& Shariff, S. (2019). Validation study of health administrative data algorithms to identify individuals experiencing homelessness and estimate population prevalence of homelessness in Ontario, Canada. BMJ Open, 9(10), 1-11. 
Schiff, J. W., Schiif, R. Turner, A., \& Bernard, K., (2015). Rural homelessness in Canada: Directions for Planning and Research. Journal of Rural and Community Development, 1O(4), 85-106.

Sokolowski, R. (2000). Transcendental phenomenology. In Proceedings of the 2oth World Congress of Philosophy (pp. 233-241). https://doi.org/10.5840/wcp202000763

Symbolic Interaction Index/Volume 32, 2009. (2009). Symbolic Interaction, 32(4), 401-403. https://doi.org/10.1525/si.2009.32.4.401

Thistle, J. A. (2017). Indigenous definition of Homelessness in Canada. https://homelesshub.ca/sites/default/files/COHIndigenousHomelessnessDefinition.pdf

Woolley, E. (2015). What are the statistics on homelessness due to divorce? https://www.homelesshub.ca/blog/what-are-statistics-homelessness-due-divorce journal focusing on theoretically-based research that addresses contemporary national and international issues. JSBHS articles include peer-reviewed research reports, brief resports, comprehensive literature reviews, books reviews, and student research. 